\title{
La discinesia vesicular continúa siendo una incógnita a resolver en problemas médicos, revisión de la literatura
}

\author{
Gallbladder dyskinesia continues to be an unknown knowledge \\ to resolve a medical problem, literature review
}

\author{
Leopoldo Herrera Chabert, ${ }^{*}$ Narcizo León Quintero, ${ }^{*}$, Enrique Llamas Prieto, ${ }^{*}, \neq$ \\ María Gema Rico Guzmán, ${ }^{*} \S$ Alfredo Ávila Toscano*đ
}

Palabras clave: Discinesia vesicular, reto, cólico, náuseas, vómito, distención abdominal.

Keywords: Gallbladder dyskinesia, challenge, colic, náusea, vomit, abdominal bloating.

${ }^{*}$ Departamento de Gastro-Cirugía. Hospital San Javier. Guadalajara, Jalisco, México.

‡ Cirugía General.

$\S$ Medicina Nuclear.

" Patólogo.

Recibido: 23/08/2019 Aceptado: 30/05/202

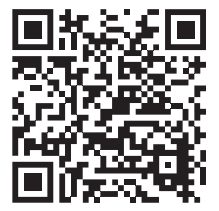

\section{RESUMEN}

Introducción: El propósito de este informe es describir que la discinesia de la vesícula biliar representa el trastorno más difuso de la motilidad gastrointestinal sin conocer el origen, el diagnóstico de la discinesia vesicular continúa siendo un desafío, especialmente para los médicos que no están bien relacionados o familiarizados con esta entidad de dolor en epigastrio o cuadrante superior derecho, sin ninguna alteración orgánica que pueda explicar los síntomas del paciente. La discinesia de la vesícula biliar debe sospecharse en pacientes con dolor biliar, en quienes las enzimas hepáticas, pancreáticas, la ecografía abdominal hepatobiliar y la endoscopia digestiva alta son normales, sin alteraciones que expliquen el cuadro clínico. Material y métodos: De 132 pacientes operados de colecistectomía, sólo 60 pacientes con discinesia vesicular se registraron en este estudio, de los cuales, sólo 55 pacientes se sometieron a medicina nuclear para gammagrafía hepatobiliar con prueba de Boyden. Todos estaban sintomáticos, y no se mitigaban sus molestias con antiácidos, procinéticos o inhibidores de la bomba de protones. Resultados: De los 60 pacientes que se sometieron a colecistectomía por cirugía laparoscópica, todos ellos han reportado de buenos a excelentes resultados tanto funcionales como sintomáticos, con una morbilidad mínima, sin muertes y sin recurrencia de la sintomatología a seis meses de seguimiento. Conclusiones: Desde la primera descripción por Krukenberg en 1903, el enfoque de la discinesia vesicular no ha ganado popularidad mundial entre los cirujanos. Creemos que cuando hay una historia clínica precisa, un examen físico completo que concluya que no hay visceromegalias y en ausencia de cálculos biliares u otra patología estructural en el ultrasonido abdominal, se debe considerar una discinesia vesicular hasta que no se demuestre lo contrario.

\section{ABSTRACT}

Introduction: The purpose of this report is to describe that gallbladder dyskinesia represents the most diffuse disorder of gastrointestinal motility without knowing the origin; the diagnosis of gallbladder dyskinesia is a challenge, particularly for doctors who are not well related or familiar with this entity of abdominal pain without any abdominal alteration that can explain the patient symptoms. Gallbladder dyskinesia should be suspected in patients with biliary pain, in which liver and pancreatic enzymes, abdominal hepatobiliary ultrasound and upper gastrointestinal endoscopy are normal, without alterations that explain the clinical picture. Material and methods: We operated 132 patients, where only 60 patients with gallbladder dyskinesia were enrolled in this study. Fiftyfive from the 60 patients underwent a (HIDA) scintigraphy with Boyden test. They were all severely symptomatic, which were not relieved by antacids, prokinetics or proton pump inhibitors. Results: Of the 60 patients who underwent to cholecystectomy by laparoscopy surgery, all of them have reported well to excellent functional and symptomatic outcomes with minimal morbidity, no deaths, and no recurrence of symptomatology, six months follow up. Conclusions: Since the first description by Krukenberg in 1903, gallbladder dyskinesia approach has not gained worldwide popularity among surgeons. It is our belief that when there are a precise history, complete physical examination that concludes that there are not visceromegalies, and in the absence by US of gallstones or another structural pathology, you should considerate a gallbladder dyskinesia until proven otherwise.

Citar como: Herrera CL, León QN, Llamas PE, Rico GMG, Ávila TA. La discinesia vesicular continúa siendo una incógnita a resolver en problemas médicos, revisión de la literatura. Cir Gen. 2020; 42 (4): 288-299. https://dx.doi. org/10.35366/101398 


\section{ANTECEDENTES HISTÓRICOS}

$\mathrm{P}_{\mathrm{o}}^{\mathrm{o}}$ osterior a la revisión del metaanálisis sistemáticamente usando "The PubMed/Medline and Scopus" de 1980 a 2016 para identificar lo relevante en la literatura, utilizando términos relacionados con la misma enfermedad como: discinesia vesicular, discinesia biliar, vesícula funcional, espasmo biliar o colecistitis acalculosa y HIDA o centellografía (colecistografía), fracción de eyección y colecistectomía. ${ }^{1,2}$

En este ejercicio se revisaron 29 estudios, incluyendo 2,891 pacientes contrastando la colecistectomía con el tratamiento médico, donde se observó que los pacientes con una fracción de eyección de la vesícula biliar (GEF) normal o por arriba de 35\% no se beneficiaron de la colecistectomía; mientras que aquellos con bajo GEF < 35\% tuvieron mayor probabilidad (riesgo relativo $[R R]=2.37$ ) de mejoría sintomática después de la cirugía.

Estos autores concluyeron que es posible que un GEF bajo proporcione alguna guía para identificar a las personas con discinesia vesicular que puedan beneficiarse de la colecistectomía; sin embargo, los datos disponibles fueron inconsistentes y se basan en estudios de baja calidad que a menudo están sujetos a los pacientes y al impacto de factores de confusión. Por estas razones, esos autores especularon que el papel de la gammagrafía y la colecistectomía en la definición y el tratamiento de este trastorno sigue sin estar claro en espera de un estudio definitivo. ${ }^{1-5}$

El primero en referirse a la discinesia vesicular fue Krukenberg en 1903. Posteriormente los patólogos Aschoff y Bacmieister y la describieron en 1909 como la estasis de la vesícula biliar que ocurre sin inflamación o sin litos biliares. ${ }^{1-5}$

El reconocimiento del dolor biliar en ausencia de cálculos biliares se describió por primera vez en la década de 1920. En 1924, Blalock6 describió a 139 pacientes con colecistitis acalculosa de 735 pacientes con enfermedad lito biliar. Ya en 1926, Whipple, ${ }^{7}$ de acuerdo con el artículo de Blalock, cuestionó la colecistectomía realizada sin una patología definida que lo justificara. En ese año, según los criterios quirúrgicos para la colecistectomía, Whipple recomendó dejar in situ una vesícula biliar acalculosa de aspecto normal, nada de lo que observaron de los 47 pacientes sometidos a colecistectomía sin evidencia de cálculos biliares, de los cuales $76.6 \%$ se mostraron asintomáticos en el seguimiento en comparación con casi $90 \%$ de los casos con litiasis vesicular. ${ }^{6}$ La colecistografía fue descrita por primera vez en 1924 por Graham y Cole, ${ }^{8}$ quienes utilizaron tetrabromofenolftaleína, una sustancia que se excreta en el árbol biliar para permitir la obtención de imágenes radiológicas de la vesícula biliar y el árbol biliar. En las décadas siguientes, varios pacientes fueron sometidos a colecistectomía en ausencia de cálculos biliares. De manera similar, otros médicos como Gleen y Mannix ${ }^{9}$ estudiaron en 1956 los resultados en pacientes que se sometieron a colecistectomía por vesículas biliares sin cálculos y no inflamadas, informando que sólo $65 \%$ de los pacientes tuvieron una mejoría en sus síntomas, 11\% informó alguna mejoría, mientras que 25\% no informó ninguna mejora en absoluto.

Con el uso creciente de colecistoquinina durante la colecistografía, Freeman y colaboradores ${ }^{10}$ en 1975 y otros han informado sobre el uso de la inyección de colecistoquinina para identificar a pacientes con enfermedad vesicular acalculosa, y quiénes pueden beneficiarse de la colecistectomía. En el estudio de Freeman de 22 pacientes con fracción de eyección disminuida o reproducción de síntomas con la inyección de colecistoquinina, 95\% informó alivio o mejoría de los síntomas.

Durante las décadas que han transcurrido desde el estudio de Freeman y colaboradores, ${ }^{10}$ ha mejorado el diagnóstico, y estudios posteriores han encontrado similitudes con altas tasas de éxito en comparación con la literatura de principios del siglo XX.

\section{PATOGÉNESIS}

Se desconoce la patogenia exacta de la disfunción de la vesícula biliar, pero se presume que el dolor asociado con la disfunción de la vesícula biliar podría estar relacionado con una señalización funcional muy compleja que causa una obstrucción funcional del flujo biliar de la vesícula biliar debido quizás a un estrechamiento no oclusivo del conducto cístico. Otra hipótesis es la anormalidad en la capa de músculo liso de la vesícula biliar que causa el 
deterioro del vaciado de la vesícula biliar, la cual fue propuesta por Merg, ${ }^{11,12}$ quien mostró una mayor incidencia de colecistitis crónica en pacientes con disfunción de la vesícula biliar en comparación con los sujetos normales. La disfunción de la vesícula biliar se ha asociado con motilidad alterada en otros órganos gastrointestinales, por ejemplo, el deterioro del vaciado de la vesícula biliar se ha observado con mayor frecuencia en adultos que sufren estreñimiento de tránsito lento, ${ }^{13}$ o diarreas en hipersensibilidad, gastroparesia, ${ }^{13}$ y acalasia. ${ }^{13}$ Esto amplía la razón de si los trastornos de la motilidad funcional a menudo son concomitantes en áreas separadas del tracto gastrointestinal, reflujo gastroesofágico (hernia de hiato), gastroparesia (enfermedad ulceropéptica), estreñimiento (síndrome de colon irritable), diarreas (gastroenteritis), distención abdominal postprandial (síndrome de intestino irritable o insuficiencia pancreática o hepática).

La colecistoquinina es un péptido neurotransmisor que se descubrió originalmente en el intestino (Ivy y Oldberg en 1928), pero se distribuye ampliamente en el sistema nervioso central (Van der Haegen en 1975). ${ }^{14-16}$

La colecistoquinina (CCK) es un péptido neurotransmisor que se secreta principalmente de dos maneras: CCK33 y CCK8, se condensan en las células I de la mucosa duodenal y el yeyuno. También se sintetizan en el sistema nervioso central, principalmente en las formas de CCK8 y CCK4.

Los dos receptores que median los efectos de CCK son CCKA y CCKB.

El receptor CCKA (A de alimentación) se encuentra principalmente en el tracto gastrointestinal, mientras que el receptor CCKB (B de cerebro) se encuentra principalmente en el cerebro. ${ }^{11,14-16}$

La colecistoquinina (CCK) ejerce múltiples efectos gastrointestinales y se libera durante las comidas, provocando vaciamiento gástrico retardado, contracción de la vesícula biliar, regulación de la motilidad intestinal y secreción de enzimas pancreáticas en comunicación con el cerebro a través del vago, mientras que en el cerebro causa un efecto anorexigénico, sueño postprandial y se especula que tiene un papel en las emociones. ${ }^{11,13-16}$

La función de la vesícula biliar implica ciclos de señalización muy complejos. Una hipótesis con respecto a la causa del dolor en la discinesia vesicular es el aumento de la presión de la vesícula biliar que al no contraerse apropiadamente se va acumulando bilis en la vesícula biliar.

En 1997 se demostró la formación de cristales en la bilis ${ }^{17}$ que forman litiasis biliar en pacientes sometidos a colecistectomía debido a discinesia vesicular; por lo tanto, la inflamación de la pared de la vesícula biliar se ha propuesto como una causa de dolor, puesto que incluso 94\% de los pacientes sometidos a cirugía muestran cambios crónicos y agudos de colecistitis en el estudio histológico. ${ }^{17,18-20}$

Otra hipótesis propuesta para la discinesia de la vesícula biliar es la existencia de hipersensibilidad generalizada en las vías neurales que conectan el cerebro y el tálamo con el intestino.

Se ha demostrado hipersensibilidad visceral en pacientes con otros trastornos biliares funcionales como en la disfunción del esfínter de Oddi. ${ }^{20}$

También se ha demostrado que los pacientes con síndrome del intestino irritable muestran una contracción alterada de la vesícula biliar en respuesta a la colecistoquinina, por lo tanto, la discinesia de la vesícula biliar puede ser el resultado de defectos en la señalización nerviosa de colecistoquinina que causa cambios en la composición de la bilis y la colecistitis crónica. ${ }^{16,17,20}$

La discinesia de la vesícula biliar representa el trastorno más difuso de la motilidad gastrointestinal.

La enfermedad por reflujo gástrico esofágico y la inactividad del colon afectan a un gran número de pacientes con discinesia vesicular, por lo que se confunde habitualmente, diagnosticándose síndrome del intestino irritable, lo que sugiere una relación entre los dos trastornos. ${ }^{19,21}$ Los receptores de colecistoquinina se expresan a través del tracto gastrointestinal y entre otras cosas, afectan la motilidad del colon y la función sensorial.

Con base en estas propiedades, los antagonistas de la colecistoquinina se han desarrollado para tratar trastornos funcionales como el síndrome del intestino irritable. ${ }^{17,19,21,22}$

Hay múltiples formas activas de colecistoquinina y se reconoce que es el neuropéptido más distribuido en el cerebro con altas 
concentraciones de éste y sus receptores en la corteza cerebral, en el bulbo olfatorio, el hipotálamo, las amígdalas, el hipocampo, el cuerpo estriado, la materia gris periacueductal y la médula espinal.

Esta distribución neuroanatómica ha generado especulaciones sobre su papel en los trastornos de ansiedad, lo que dio lugar a múltiples estudios incluidos los antagonistas de la colecistoquinina. ${ }^{15,16}$

Se cree que la dismotilidad de la vesícula biliar desempeña un papel central en la patogénesis.

La dismotilidad de la vesícula biliar puede ser el resultado de un trastorno metabólico inicial (es decir, bilis sobresaturada con colesterol), que aumenta la viscosidad biliar, o un trastorno de motilidad primaria en ausencia, al menos inicialmente, de cualquier anormalidad en la composición de la bilis. ${ }^{17,21}$ El trastorno funcional de la vesícula biliar se ha asociado con un vaciado gástrico anormal y un tránsito colónico anormal, lo que sugiere un posible trastorno generalizado de la motilidad gastrointestinal. ${ }^{11,12,17,19,21}$

\section{DIAGNÓSTICO}

En 1923 Westphal la describe como "disfunción del sistema nervioso autónomo de la vesícula biliar". ${ }^{1,3}$ La discinesia de la vesícula biliar se ha postulado desde hace varias décadas como una entidad que constituye un trastorno en la motilidad de la vesícula biliar, que se manifiesta clínicamente con dolor biliar en el cuadrante superior derecho o en epigastrio que en un gran número de pacientes es posible que se irradie a la región infraescapular derecha, el dolor a menudo se asocia con diaforesis, náuseas y vómito, puede acompañarse también de distención abdominal, estreñimiento o evacuaciones diarreicas y/o reflujo G/E. ${ }^{21,23}$

El dolor se estabiliza en menos de una hora, que varía de intensidad moderada a insoportable y una vez que se ha estabilizado, el dolor generalmente dura al menos 30 minutos y luego desaparece lentamente durante varias horas. ${ }^{21,23,24}$

En un gran porcentaje de pacientes en quienes el ultrasonido de abdomen es negativo para colelitiasis, se hacen equivocadamente un sinfín de diagnósticos erróneos como de colon irritable, enfermedad ácido péptica, patología hepática o pancreática, trayendo como consecuencia la solicitud de exámenes no apropiados con costos innecesarios y la indicación de prescripciones inadecuadas, lo cual redunda en mayores costos de la atención y lo que es más grave, la persistencia de la sintomatología que no mejora con la ingesta de antiácidos, inhibidores de la bomba de protones o procinéticos, o que reaparecen esos síntomas posterior a la suspensión de los medicamentos. ${ }^{21,23,24}$

La prevalencia de la discinesia de la vesícula biliar se estima en $8 \%$ en hombres y $22 \%$ en mujeres. ${ }^{21,25}$ Definitivamente, el diagnóstico de discinesia vesicular es un reto, particularmente para los médicos que no están bien relacionados o familiarizados con esta entidad de dolor en el cuadrante superior derecho, acompañado de diaforesis, náuseas y vómitos gastrobiliar o alimenticio y prácticamente siempre con un ultrasonido abdominal hepatobiliar sin evidencia de litiasis, lodo o inflamación de la vesícula biliar, con pruebas normales de función hepática, pancreática y con una endoscopia esofágica, gastroduodenal normal. ${ }^{21,23,24}$

Los criterios de Roma IV incluyen ${ }^{26}$ "fracción de eyección baja de la vesícula biliar" posterior a la estimulación alimenticia como criterio "de apoyo" para hacer este diagnóstico. ${ }^{5,14,27,28}$

La discinesia de la vesícula biliar constituye aproximadamente $80 \%$ de los pacientes con "enfermedad de la vesícula biliar no especificada" en los Estados Unidos, donde en los últimos años se han triplicado los ingresos hospitalarios por esta enfermedad, con un aumento de $700 \%$ en la población pediátrica, constituyendo de 5 a $20 \%$ de las colecistectomías en pacientes adultos y de 10 a 50\% en la población pediátrica de ese país. ${ }^{21,25}$

Los criterios de Roma III para el diagnóstico de trastornos funcionales de la vesícula biliar lo definieron como dolor de tipo biliar con enzimas hepáticas y pancreáticas normales, junto con la exclusión por US abdominal de otras enfermedades estructurales, incluidos los cálculos biliares y una endoscopia alta normal.

Los criterios de Roma III definen la discinesia vesicular como la existencia de diversos síntomas que tienen variaciones durante periodos como: 
1. Un episodio de dolor de al menos $30 \mathrm{mi}-$ nutos.

2. Síntomas recurrentes en distintos intervalos (no diario).

3. Dolor en incremento paulatino.

4. Dolor moderado a severo que interrumpe en ocasiones las actividades cotidianas y que puede requerir evaluación en el servicio de urgencias.

5. El dolor no se alivia con evacuaciones intestinales.

6. El dolor no disminuye con los cambios de posición.

7. El dolor no se alivia con el consumo de antiácidos, inhibidores de la bomba de protones o procinéticos.

8. Exclusión de otras enfermedades estructurales que puedan explicar los síntomas.

En la versión de los criterios de Roma IV para el diagnóstico de trastornos funcionales, la "fracción de eyección baja" de la vesícula biliar se ha incluido como criterio de apoyo en el diagnóstico de discinesia vesicular. ${ }^{5,14,28}$

Los criterios de Roma IV para el trastorno funcional de la vesícula biliar requieren: ${ }^{26}$ dolor biliar, que se define como dolor en el epigastrio y/o en el cuadrante superior derecho que cumple con todos los criterios siguientes:

1. Dolor progresivo hasta un nivel constante y dura al menos 30 minutos.

2. Dolor que ocurre a diferentes intervalos (por lo general no diariamente).

3. Dolor lo suficientemente grave para interrumpir las actividades cotidianas o acudir al servicio de urgencias $(<20 \%)$ con evacuaciones intestinales o que se alivie con el cambio postural o la supresión ácida.

Los criterios que respaldan el dolor biliar, pero que a la vez no son necesarios, incluyen: dolor asociado con náuseas y vómitos, radiación de dolor en la región infrascapular derecha y dolor que despierta al paciente. Ausencia de cálculos biliares, inflamación u otra patología estructural.

Los criterios que respaldan el trastorno funcional de la vesícula biliar, pero que no son obligatorios, incluyen: la fracción de eyección de la vesícula biliar (GEF) baja en la gammagra- fía hepatobiliar menor de 35\% que se realiza en el departamento de medicina nuclear y que dependerá de una infusión intravenosa de CCK, o una comida grasosa oral y un tiempo de 5, 30 o 40 minutos. En nuestro hospital utilizamos en todos los pacientes estimulación oral con $40 \mathrm{mi}-$ nutos como tiempo total postestimulación para leer la fracción de eyección de la vesícula biliar.

Se recomendó un límite de 35\% para definir el límite inferior normal de $\mathrm{GEF}^{5,14,28}$ que puede diagnosticar la discinesia de la vesícula biliar y predecir una buena respuesta a la colecistectomía. ${ }^{5,14,28}$

\section{Presentación clínica}

Dolor postprandial o distensión abdominal acompañado de náuseas relacionadas con intolerancia a los alimentos grasos, que no se alivian con antiácidos, inhibidores de la bomba de protones o procinéticos.

Náuseas $52 \%$, vómitos $43 \%$, distensión abdominal $21 \%$, saciedad temprana $21 \%$, estreñimiento $21 \%$, diarrea $13 \%$, síntomas que ocurren una o más veces en un periodo de 12 meses y donde no hay evidencia de patología o anormalidad estructural que explique el origen de los síntomas. 21,23,24,29

En la primera entidad en la que uno debe pensar en un paciente con dolor epigástrico, $\mathrm{O}$ $\mathrm{CSD}$, distensión abdominal y vómitos gastrobiliares 15-20 minutos después de la ingesta de alimentos, particularmente cuando se asocia con pruebas de función hepática y pancreática (aminotransferasas, gamma-glutamil transpeptidasa, fosfatasa alcalina, bilirrubina total y conjugada, amilasa, lipasa, BH, VSG y PCR normales) con endoscopia esófago-gastroduodenal normal y con un USG abdominal sin evidencia de litiasis o inflamación de la vesícula biliar, debe considerarse una discinesia vesicular hasta que no se demuestre lo contrario y dentro del protocolo para seguir esta entidad es realizar una estudio de la vesícula biliar en el servicio de medicina nuclear (Figura 1) con HIDA, también conocida como colecistografía por gammagrafía hepatobiliar con 99 de tecnecio (Tc) marcado con ácido hepático iminodiacético (HIDA), que se administra como un bolo intravenoso del marcador radio marcado, el cual es absorbido por el hígado y concentrado en la vesícula biliar 
como la bilis, observando ya la vesícula biliar al minuto 20 y después de 60 minutos de llenado se le administra al paciente una inyección de un medicamento llamado colecistoquinina (CCK) o se le permite comer una comida grasosa que debe realizarse en ese momento, ya que tanto CCK administrada IV como la comida oral grasosa (prueba de Boyden) son señales para que la vesícula biliar se contraiga, y si la fracción de eyección de la vesícula biliar (GEF) es inferior a 35\% después de 40 minutos de medición, la prueba se considera universalmente positiva para la discinesia de la vesícula biliar (Krishnamurthy lo describió en 1981).5,14,28

La utilidad de examinar por medicina nuclear con HIDA la discinesia de la vesícula biliar se centra en su capacidad para evaluar indirectamente la contractilidad de la vesícula biliar en respuesta a la estimulación (hoy en día de una ingesta de comida grasosa), donde los resultados se expresan en términos del porcentaje del marcador radioactivo vaciado en la fracción de eyección de la vesícula biliar (GEF) (Figuras 2 y 3); 17 estudios anteriores que usaron colecistografía oral y estimulación con CCK IV, informaron que un grupo de pacientes con dolor biliar y sin evidencia

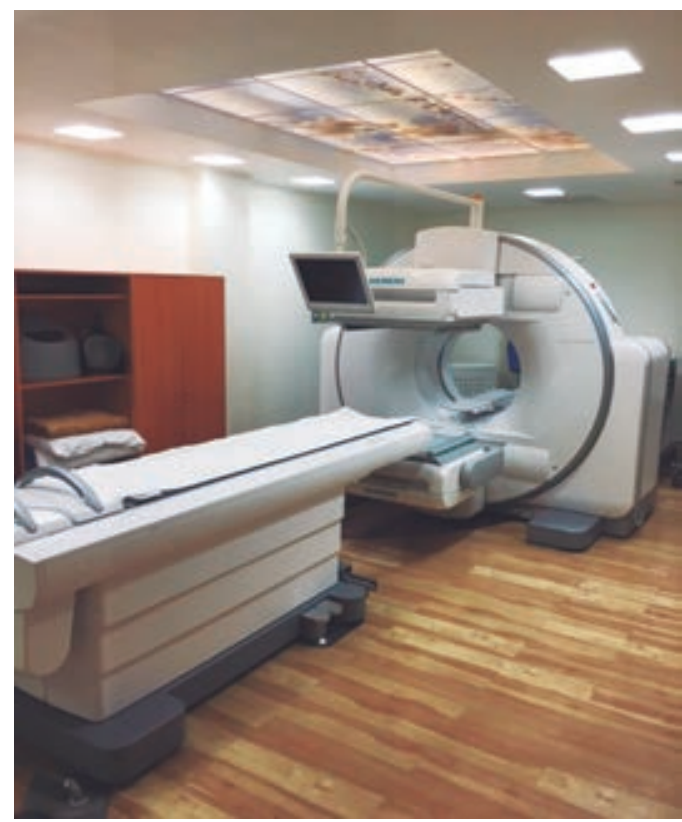

Figura 1: SIEMENS SYMBIA INTEVO medicina nuclear más CT Scan.

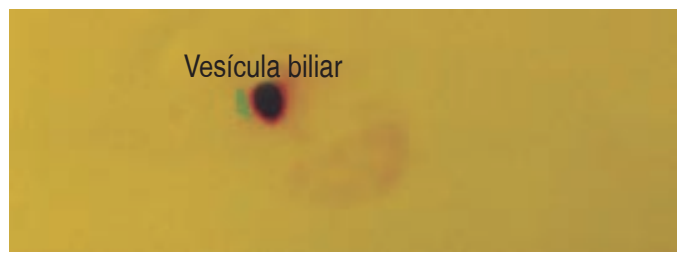

Curvas de fracción de eyección

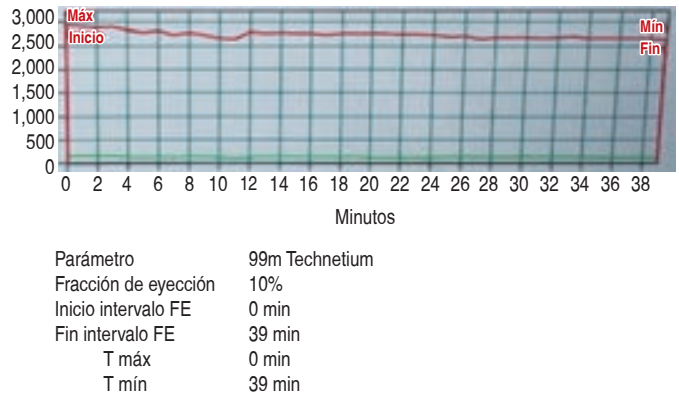

Figura 2: Ácido iminodiacético hepatobiliar (HIDA) que muestra la vesicula biliar FE (fracción de eyección) 10\% positiva para discinesia de vesícula biliar.

de cálculos biliares tenían una vesícula biliar poco contráctil, que se remonta a la década de $1970 .{ }^{28}$ Después de 40 años las técnicas de colecistografía en medicina nuclear (Figura 1) han mejorado considerablemente, y la colecistectomía se ha utilizado durante bastante tiempo para tratar pacientes con bajo GEF inferior a $35 \%$, obteniendo excelentes resultados a pesar de la naturaleza algo vaga de este trastorno mal definido y las limitaciones de las pruebas de diagnóstico propuestas. Sin embargo, la incidencia de colecistectomía como tratamiento de la discinesia vesicular (es decir, individuos sin cálculos biliares u otra patología orgánica de la vesícula biliar) ha aumentado rápidamente en los Estados Unidos en comparación con otras partes del mundo, particularmente desde el surgimiento del abordaje laparoscópico. 5, 14,19,20,28

Por lo tanto, a pesar de años de investigación y debate, aún existen controversias con respecto al diagnóstico y el pronóstico de la discinesia vesicular así como la utilidad de la colecistectomía para la discinesia de la vesícula biliar. Nuestro objetivo, por lo tanto, fue analizar en una revisión sistemática el desempeño de la fracción de eyección de la vesícula biliar menor de 35\% en la predicción de la respuesta 


\author{
Figura 3:

Figura 3:
Ácido
iminodiacético
hepatobiliar (HIDA)
que muestra la
vesícula biliar EF
$10 \%$ compatible
con discinesia de
la vesícula biliar.

$13 / 04 / 2016$

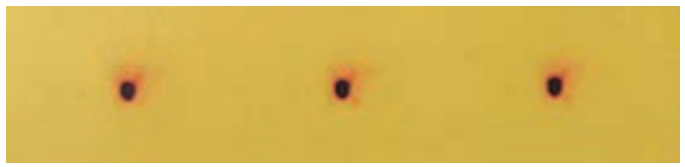

$60 s$

$120 \mathrm{~s}$

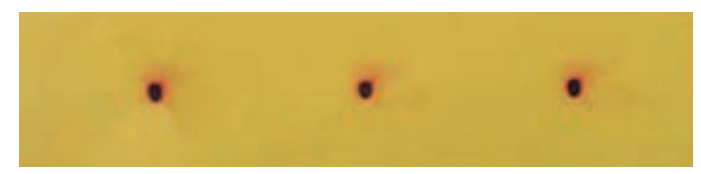

$5 \min$

$6 \min$

7 min

a la colecistectomía en pacientes con discinesia vesicular.

Hay que tener en cuenta y recabarlo en la historia clínica que varias afecciones médicas pueden disminuir la GEF como diabetes mellitus, embarazo, enfermedad celíaca y síndrome del intestino irritable así como la administración de medicamentos como anticolinérgicos, opioides, AINEs, bloqueadores de los canales de calcio, anticonceptivos orales, antagonistas de los receptores de histamina ${ }^{2}$ y benzodiacepinas, los cuales deben suspenderse por lo menos 24 horas antes del estudio. $5,14,18,28$

\section{MATERIAL Y MÉTODOS}

De junio de 2015 hasta junio de 2019 hemos operado mediante cirugía laparoscópica 132 pacientes; hubo 38 hombres (28.7\%) y 94 mujeres $(71.2 \%)$, con una edad media de 28 años (rango, 14-58 años). Sólo los pacientes con discinesia vesicular se incluyeron en este estudio. Pacientes con litiasis vesicular fueron excluidos del estudio.

Todos los pacientes se sometieron a colecistectomía por cirugía laparoscópica.

De 60 pacientes diagnosticados con discinesia vesicular, 42 fueron mujeres (70\%) y 18 hombres (30\%) (Tabla 1).

Todos los pacientes se sometieron a una ecografía abdominal, donde no se observaron cálculos, lodo, ni inflamación de la vesícula biliar, seguidos por 55 pacientes con gammagrafía hepatobiliar; ácido iminodiacético hepático (HIDA) marcado con tecnecio (Tc) $99 \mathrm{~mm}$ y con estimulación por una alimentación oral estándar con grasa, mostrando una fracción de

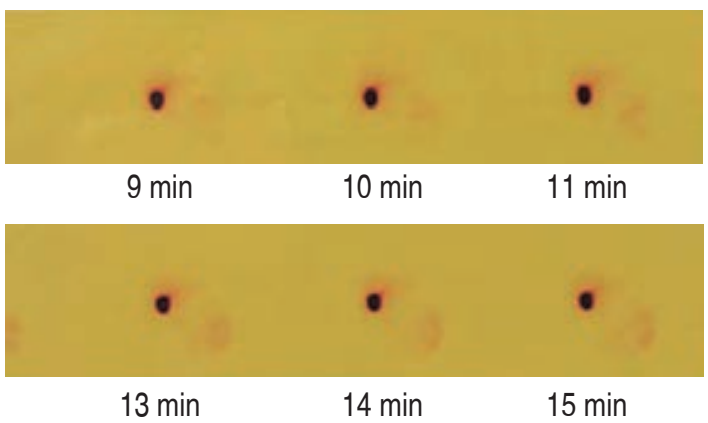

eyección de la vesícula biliar (GEF) menos de $35 \%$, hubo cinco pacientes a quienes no se les realizó HIDA, debido a anormalidades previas de la vesícula biliar por US abdominal como capuchón o gorro frigio o presencia de tabique en cuello o en fondo de la vesícula biliar sin litiasis, lodo o inflamación.

Los diagnósticos histopatológicos de los 60 pacientes operados fueron compatibles con colecistitis crónica agudizada y que coincidía con adherencias del epiplón mayor, duodeno, colon transverso a bolsa de Hartman, o cuerpo, o fondo vesicular o que el epiplón mayor cubría completamente toda la vesícula biliar como se aprecia en las Figuras 4 a 6 .

En la revisión de histopatología, 10 tenían lodo y colesterolosis de la mucosa biliar (Figuras 7 y 8), en dos se detectaron pólipos y tres tenían segmentación de la vesícula biliar, uno en fondo y dos en bolsa de Hartmann que no fueron detectados por US abdominal.

Del total de los pacientes en este estudio, $100 \%$ presentaron síntomas de dolor abdominal superior, acompañadas de diaforesis, náuseas, vómito, distención abdominal, estreñimiento, reflujo gastroesofágico postprandial en ausencia de otras causas atribuibles y asociadas con fracciones de eyección de la vesícula biliar bajas (GEF) menor de 35\%, y no hubo evidencia de hernia de hiato por endoscopia en los pacientes que referían reflujo $\mathrm{G} / \mathrm{E}$.

El dolor abdominal, las náuseas, vómito, estreñimiento y la distención abdominal fueron los síntomas más comunes, y diaforesis cuando el dolor era tan intenso que tenían que acudir a urgencias o éste cedía en un lapso de 30 minutos. 
Tabla 1: Casos de discinesia vesicular, patología y síntomas acompañantes.

\begin{tabular}{|c|c|c|c|c|}
\hline Sexo & Edad & Patología & $\begin{array}{c}F E \\
\text { vesicular } \\
(\%)\end{array}$ & Síntomas acompañantes \\
\hline 1. $\mathrm{F}$ & 32 & Lodo & 20 & Dolor en epigastrio postprandial, náusea, vómito, distensión abdominal, estreñimiento \\
\hline 2. $\mathrm{F}$ & 32 & Lodo & 35 & Dolor en epigastrio postprandial, náusea, vómito, distensión abdominal \\
\hline 3. $\mathrm{M}$ & 39 & Lodo & 28 & Dolor en epigastrio postprandial, náusea, vómito, distensión abdominal, estreñimiento \\
\hline 4. $\mathrm{F}$ & 34 & Colecistitis & 2 & Dolor en epigastrio postprandial, náusea, vómito, distensión abdominal, estreñimiento \\
\hline 5. F & 52 & Colecistitis & 15 & Dolor en epigastrio postprandial, náusea, vómito, distensión abdominal \\
\hline 6. F & 57 & Colecistitis & 20 & Dolor en epigastrio postprandial, náusea, vómito, distensión abdominal \\
\hline 7. $\mathrm{F}$ & 27 & Colecistitis & 10 & $\begin{array}{l}\text { Dolor en epigastrio, náusea, vómito, distensión abdominal, estreñimiento, reflujo } \\
\text { gastroesofágico }\end{array}$ \\
\hline 8. M & 32 & Colecistitis & 3 & Dolor en epigastrio postprandial, náusea, vómito, distensión abdominal \\
\hline 9. F & 20 & Colecistitis & 7 & $\begin{array}{l}\text { Dolor en epigastrio, náusea, vómito, distensión abdominal, estreñimiento, reflujo } \\
\text { gastroesofágico }\end{array}$ \\
\hline 10. F & 25 & Colecistitis & 35 & Dolor en epigastrio postprandial, náusea, vómito, distensión abdominal \\
\hline 11. F & 19 & Colecistitis & 8 & $\begin{array}{l}\text { Dolor en epigastrio, náusea, vómito, distensión abdominal, estreñimiento, reflujo } \\
\text { gastroesofágico }\end{array}$ \\
\hline 12. $\mathrm{F}$ & 28 & Colecistitis & 35 & Dolor en epigastrio postprandial, náusea, vómito, distensión abdominal \\
\hline 13. F & 53 & Colecistitis & 35 & Dolor en epigastrio postprandial, náusea, vómito, distensión abdominal \\
\hline 14. F & 22 & Colecistitis & 20 & $\begin{array}{l}\text { Dolor en epigastrio postprandial, náusea, vómito, distensión abdominal, reflujo } \\
\text { gastroesofágico }\end{array}$ \\
\hline 15. F & 18 & Colecistitis & 1.8 & $\begin{array}{l}\text { Dolor en epigastrio postprandial, náusea, vómito, distensión abdominal, reflujo } \\
\text { gastroesofágico }\end{array}$ \\
\hline 16. F & 57 & $\begin{array}{l}\text { Lodo y } \\
\text { pólipo }\end{array}$ & 30 & Dolor en CSD postprandial, náusea, vómito, distensión abdominal, estreñimiento \\
\hline 17. F & 26 & Colecistitis & 16 & $\begin{array}{l}\text { Dolor en epigastrio postprandial, náusea, vómito, distensión abdominal, reflujo } \\
\text { gastroesofágico }\end{array}$ \\
\hline 18. $\mathrm{F}$ & 40 & Colecistitis & 24 & Dolor en epigastrio postprandial, náusea, vómito, distensión abdominal \\
\hline 19. F & 19 & Colecistitis & 15 & $\begin{array}{l}\text { Dolor en epigastrio, náusea, vómito, distensión abdominal, reflujo gastroesofágico, } \\
\text { estreñimiento }\end{array}$ \\
\hline 20. F & 25 & Colecistitis & 24 & Dolor en epigastrio postprandial, náusea, vómito, distensión abdominal \\
\hline 21. $\mathrm{M}$ & 17 & Colecistitis & 35 & Dolor en epigastrio postprandial, náusea, vómito, distensión abdominal \\
\hline 22. $\mathrm{M}$ & 42 & Colecistitis & 35 & Dolor en epigastrio postprandial, náusea, vómito, distensión abdominal \\
\hline 23. $\mathrm{F}$ & 54 & Gorro frigio & 0 & Dolor en epigastrio postprandial, náusea, vómito, distensión abdominal, estreñimiento \\
\hline 24. F & 30 & Colecistitis & 24 & Dolor en epigastrio postprandial, náusea, vómito, distensión abdominal \\
\hline 25. M & 49 & Lodo & 2 & Dolor en epigastrio postprandial, náusea, vómito, distensión abdominal \\
\hline 26. F & 18 & Gorro frigio & 3 & $\begin{array}{l}\text { Dolor en epigastrio postprandial, náusea, vómito, distensión abdominal, reflujo } \\
\text { gastroesofágico }\end{array}$ \\
\hline 27. $\mathrm{F}$ & 36 & Colecistitis & 25 & $\begin{array}{l}\text { Dolor en epigastrio postprandial, náusea, vómito, distensión abdominal, reflujo } \\
\text { gastroesofágico }\end{array}$ \\
\hline 28. $\mathrm{M}$ & 37 & Colecistitis & 28 & Dolor en epigastrio postprandial, náusea, vómito, distensión abdominal \\
\hline 29. F & 55 & Gorro frigio & 3 & $\begin{array}{l}\text { Dolor en epigastrio postprandial, náusea, vómito, distensión abdominal, reflujo } \\
\text { gastroesofágico }\end{array}$ \\
\hline 30. F & 51 & Lodo & 0 & Dolor continuo en epigastrio y CSD, irradiación subescapular derecha, estreñimiento \\
\hline 31. M & 25 & Colecistitis & 13 & $\begin{array}{l}\text { Dolor en epigastrio postprandial, náusea, vómito, distensión abdominal, reflujo } \\
\text { gastroesofágico }\end{array}$ \\
\hline 32. F & 32 & Gorro frigio & 3 & $\begin{array}{l}\text { Dolor en epigastrio, náusea, vómito, distensión abdominal, estreñimiento, reflujo } \\
\text { gastroesofágico }\end{array}$ \\
\hline 33. F & 37 & Gorro frigio & 3 & Dolor en epigastrio postprandial, náusea, vómito, distensión abdominal \\
\hline 34. F & 24 & Gorro frigio & 3 & Dolor en epigastrio postprandial, náusea, vómito, distensión abdominal \\
\hline
\end{tabular}


Continúa la Tabla 1: Casos de discinesia vesicular, patología y síntomas acompañantes.

\begin{tabular}{|c|c|c|c|c|}
\hline Sexo & Edad & Patología & $\begin{array}{c}F E \\
\text { vesicular } \\
(\%)\end{array}$ & Síntomas acompañantes \\
\hline 35. F & 27 & Gorro frigio & 3 & $\begin{array}{l}\text { Dolor en epigastrio postprandial, náusea, vómito, distensión abdominal, reflujo } \\
\text { gastroesofágico }\end{array}$ \\
\hline 36. $\mathrm{M}$ & 23 & Gorro frigio & 3 & $\begin{array}{l}\text { Dolor en epigastrio, náusea, vómito, distensión abdominal, estreñimiento, reflujo } \\
\text { gastroesofágico }\end{array}$ \\
\hline 37. $\mathrm{M}$ & 29 & Colecistitis & 24 & Dolor en epigastrio postprandial, náusea, vómito, distensión abdominal \\
\hline 38. $\mathrm{F}$ & 58 & Lodo & 0 & Dolor en epigastrio postprandial, náusea, vómito, distensión abdominal, estreñimiento \\
\hline 39. M & 33 & Colecistitis & 32 & Dolor en epigastrio postprandial, náusea, vómito, distensión abdominal \\
\hline 40. F & 24 & Colecistitis & 35 & Dolor en epigastrio postprandial, náusea, vómito, distensión abdominal, estreñimiento \\
\hline 41. $\mathrm{M}$ & 23 & & & $\begin{array}{l}\text { Gorro frigio dolor en epigastrio postprandial, náusea, vómito, distensión abdominal, } \\
\text { reflujo gastroesofágico }\end{array}$ \\
\hline 42. F & 25 & & & $\begin{array}{l}\text { Gorro frigio dolor en epigastrio postprandial, náusea, vómito, distensión abdominal, } \\
\text { estreñimiento }\end{array}$ \\
\hline 43. M & 40 & Colecistitis & 32 & Dolor en epigastrio postprandial, náusea, vómito, distensión abdominal, estreñimiento \\
\hline 44. F & 34 & Lodo & 1 & $\begin{array}{l}\text { Dolor en epigastrio, náusea, vómito, distensión abdominal, reflujo gastroesofágico, } \\
\text { estreñimiento }\end{array}$ \\
\hline 45. M & 57 & Lodo & 0 & Dolor en epigastrio postprandial, náusea, vómito, distensión abdominal, estreñimiento \\
\hline 46. $\mathrm{M}$ & 29 & Pólipo & 25 & $\begin{array}{l}\text { Dolor en CSD postprandial, náusea, distensión abdominal, reflujo gastroesofágico, } \\
\text { estreñimiento }\end{array}$ \\
\hline 47. $\mathrm{F}$ & 20 & Lodo & 28 & Dolor en CSD postprandial, náusea, vómito, distensión abdominal, estreñimiento \\
\hline 48. $\mathrm{M}$ & 47 & Colecistitis & 32 & Dolor en epigastrio postprandial, náusea, vómito, distensión abdominal, estreñimiento \\
\hline 49. F & 20 & & & $\begin{array}{l}\text { Gorro frigio dolor en epigastrio postprandial, náusea, vómito, distensión abdominal, } \\
\text { estreñimiento }\end{array}$ \\
\hline 50. F & 20 & Colecistitis & 10 & Dolor en epigastrio postprandial, náusea, vómito, distensión abdominal, estreñimiento \\
\hline 51. F & 40 & Colecistitis & 1 & Dolor en epigastrio postprandial, náusea, vómito, distensión abdominal, estreñimiento \\
\hline 52. F & 26 & Colecistitis & 0 & $\begin{array}{l}\text { Dolor en epigastrio postprandial, náusea, vómito, distensión abdominal, reflujo } \\
\text { gastroesofágico }\end{array}$ \\
\hline 53. F & 23 & Colecistitis & 35 & Dolor en epigastrio postprandial, náusea, vómito, distensión abdominal, estreñimiento \\
\hline 54. F & 32 & Colecistitis & 27 & Dolor en epigastrio postprandial, náusea, diarrea, distención abdominal, estreñimiento \\
\hline 55. F & 36 & Colecistitis & 24 & Dolor en epigastrio postprandial, náusea, vómito, distensión abdominal, estreñimiento \\
\hline 56. M & 26 & Colecistitis & 21 & Dolor en epigastrio postprandial, náusea, vómito, distensión abdominal, estreñimiento \\
\hline 57. $\mathrm{M}$ & 29 & & & $\begin{array}{l}\text { Gorro frigio dolor en epigastrio postprandial, náusea, vómito, distensión abdominal, } \\
\text { reflujo gastroesofágico }\end{array}$ \\
\hline 58. F & 20 & & & $\begin{array}{l}\text { Gorro frigio dolor en epigastrio postprandial, náusea, vómito, distensión abdominal, } \\
\text { reflujo gastroesofágico }\end{array}$ \\
\hline 59. F & 14 & Lodo & 9 & $\begin{array}{l}\text { Dolor en epigastrio postprandial, náusea, vómito, distensión abdominal, reflujo } \\
\text { gastroesofágico }\end{array}$ \\
\hline 60. F & 35 & Colecistitis & 34 & Dolor en epigastrio postprandial, náusea, vómito, distensión abdominal, estreñimiento \\
\hline
\end{tabular}

La GEF media fue de $26.0 \%$.

A todos los pacientes se les siguió por seis meses, no hubo ninguna pérdida, todas las preguntas que se les hicieron fueron relativas a sus síntomas principales antes de la cirugía tomados del expediente clínico y la satisfacción posterior a la cirugía. Todos los pacientes revelaron que los síntomas fueron completamente aliviados, incluyendo los de reflujo G/E posterior a la colecistectomía. 


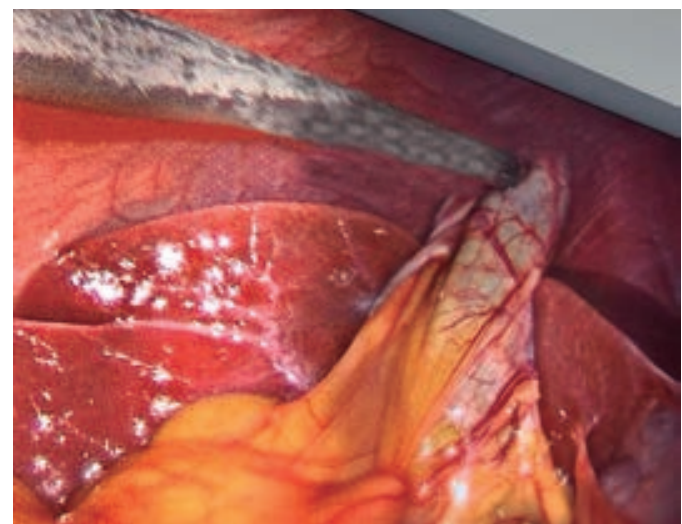

Figura 4: Observe las adherencias del proceso crónico. Múltiples adherencias, prácticamente no se identifica ninguna estructura de la vesícula y en la mayoría de estos casos de mucha inflamación el duodeno está adherido a la vesícula.

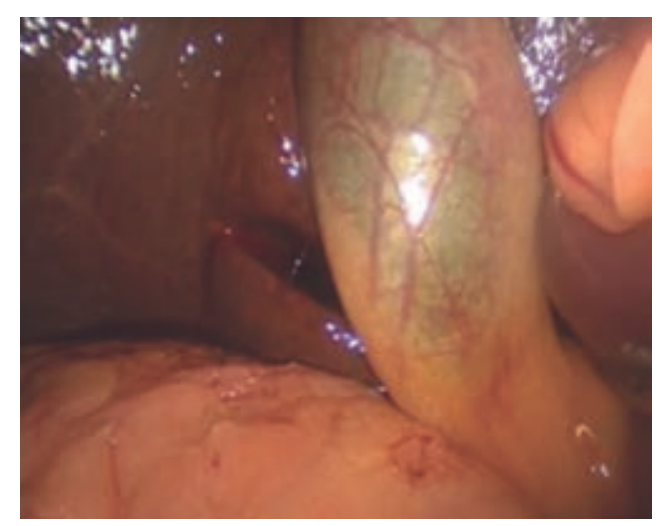

Figura 5: Observe la inflamación en la bolsa de Hartman de un proceso crónico.

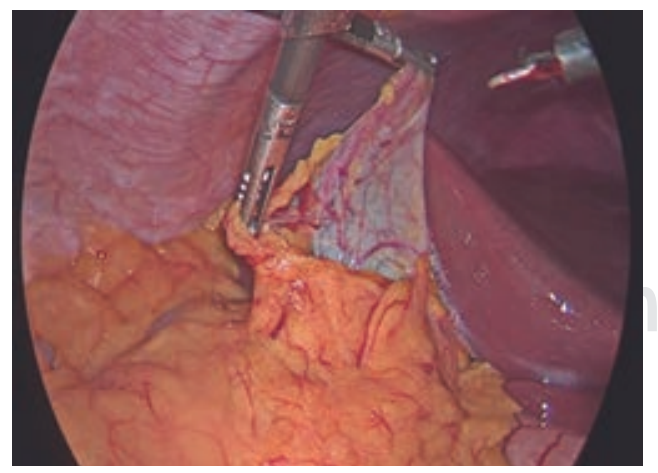

Figura 6: Observe la adherencia del epiplón mayor a toda la vesícula por un proceso inflamatorio crónico que no se percibió en el US abdominal.
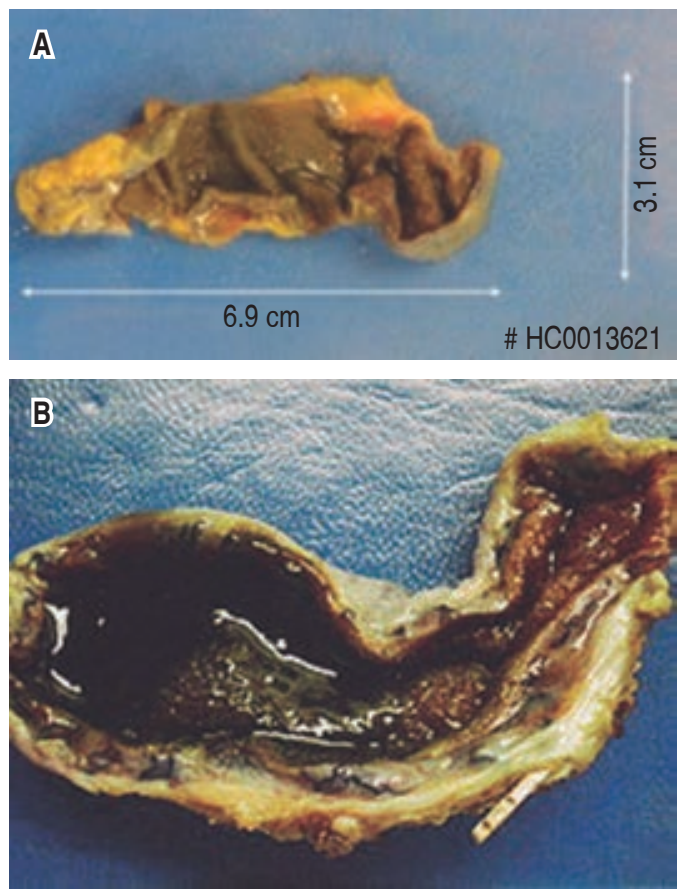

Figura 7: Observe la inflamación de la vesícula biliar, la mucosa congestiva y edematosa colesterolosis de la mucosa (A) sin litiasis y lodo (B).

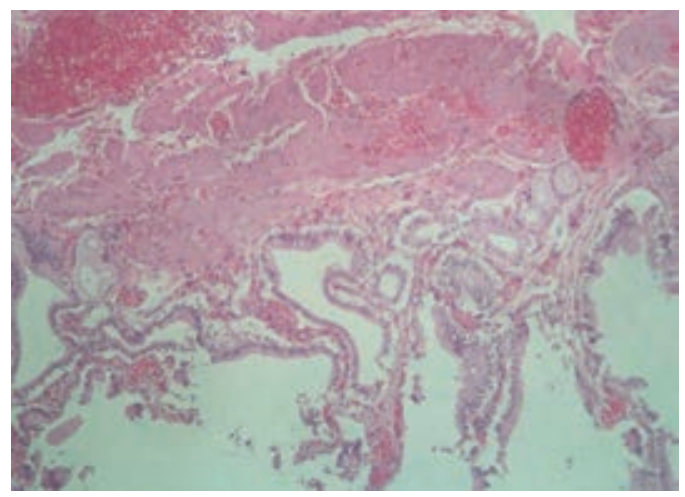

Figura 8: Pared vesicular edematosa y congestiva, infiltrado inflamatorio de tipo mixto de predominio polimorfonuclear que afecta hasta la muscular.

\section{RESULTADOS}

De los 60 pacientes que se sometieron a colecistectomía por cirugía laparoscópica por discinesia vesicular, todos reportaron de buenos a excelentes resultados funcionales $y$ sintomáticos con una morbilidad mínima, sin 
muertes, sin complicaciones, sin infecciones y sin recurrencia de la sintomatología.

\section{CONCLUSIÓN}

La discinesia de la vesícula biliar continúa siendo más frecuente en mujeres que en hombres, en personas más jóvenes que en adultos y se caracteriza clínicamente por síntomas de dolor de tipo biliar en ausencia de cálculos biliares u otra patología estructural.

La discinesia de la vesícula biliar sigue siendo un reto y un misterio clínico para los cirujanos gastroenterólogos.

La colecistectomía ha mostrado eficacia para curar los síntomas en más de 90\% de los pacientes. ${ }^{4}$

Para evitar el diagnóstico tardío debe usarse el HIDA con estimulación alimenticia lo más pronto posible en la evaluación de los cólicos biliares con ecografía negativa.

\section{REFERENCIAS}

1. Strode JE. Biliary dyskinesia from the surgical viewpoint. Ann Surg. 1943; 117: 198-206.

2. Gudsoorkar VS, Oglat A, Jain A, Raza A, Quigley EMM. Systematic review with meta-analysis: cholecystectomy for biliary dyskinesia-what can the gallbladder ejection fraction tell us? Aliment Pharmacol Ther. 2019; 49: 654-663.

3. Barnes SL, Clark DM, Schwartz RW. Biliary dyskinesia: a brief review. Curr Surg. 2004; 61: 428-434.

4. Singhal V, Szeto P, Norman H, Walsh N, Cagir B, VanderMeer TJ. Biliary dyskinesia: how effective is cholecystectomy? J Gastrointest Surg. 2012; 16: 135 140; discussion 140-141.

5. Dave RV, Pathak S, Cockbain AJ, Lodge JP, Smith AM, Chowdhury FU, et al. Management of gallbladder dyskinesia: patient outcomes following positive ${ }^{99}$ mtechnetium (Tc)-labelled hepatic iminodiacetic acid (HIDA) scintigraphy with cholecystokinin (CCK) provocation and laparoscopic cholecystectomy. Clin Radiol. 2015; 70: 400-407.

6. Blalock AA. A statistical study of 888 cases of biliary tract disease. Johns Hopkins Hosp Bull. 1924; 35: 391-409.

7. Whipple AO. Surgical criteria for cholecystectomy. Bull N Y Acad Med. 1926; 2: 302-306.

8. Graham EA, Cole WA Roentgenologic examination of the gallbladder Preliminary report of a new method utilizing intravenous injection of tetrabromophenophthalein. JAMA. 1924; 82: 613614.

9. Glenn F, Mannix H Jr. The acalculous gallbladder. Ann Surg. 1956; 144: 670-680
10. Freeman JB, Cohen WN, DenBesten L. Cholecystokinin cholangiography and analysis of duodenal bile in the investigation of pain in the right upper quadrant of the abdomen without gallstones. Surg Gynecol Obstet. 1975; 140: 371-376.

11. Merg AR, Kalinowski SE, Hinkhouse MM, Mitros FA, Ephgrave KS, Cullen JJ. Mechanisms of impaired gallbladder contractile response in chronic acalculous cholecystitis. J Gastrointest Surg. 2002; 6: 432-437.

12. Amaral J, Xiao ZL, Chen Q, Yu P, Biancani P, Behar J. Gallbladder muscle dysfunction in patients with chronic acalculous disease. Gastroenterology. 2001; 120: 506-511.

13. Penning C, Gielkens HA, Delemarre JB, Lamers CB, Masclee AA. Gall bladder emptying in severe idiopathic constipation. Gut. 1999; 45: 264-268.

14. Dauer M, Lammert F. Mandatory and optional function tests for biliary disorders. Best Pract Res Clin Gastroenterol. 2009; 23: 441-451.

15. Grace PA, Poston GJ, Williamson RC. Biliary motility. Gut. 1990; 31: 571-582.

16. Griebel G. Is there a future for neuropeptide receptor ligands in the treatment of anxiety disorders? Pharmacol Ther. 1999; 82: 1-61.

17. Velanovich V. Biliary dyskinesia and biliary crystals: a prospective study. Am Surg. 1997; 63: 69-74.

18. Adams DB. Biliary dyskinesia: does it exist? If so, how do we diagnose it? Is laparoscopic cholecystectomy effective or a sham operation? J Gastrointest Surg. 2013; 17: 1550-1552.

19. Hansel SL, DiBaise JK. Functional gallbladder disorder: gallbladder dyskinesia. Gastroenterol Clin North Am. 2010; 39: 369-379.

20. Cotton PB, Elta GH, Carter CR, Rome IV. Gallbladder and sphincter of Oddi disorders. Gastroenterology. 2016; 150: 1420-1429.

21. Kraag N, Thijs C, Knipschild P. Dyspepsia--how noisy are gallstones? A meta-analysis of epidemiologic studies of biliary pain, dyspeptic symptoms, and food intolerance. Scand J Gastroenterol. 1995; 30: 411-421.

22. Francis G, Baillie J. Gallbladder dyskinesia: fact or fiction? Curr Gastroenterol Rep. 2011; 13: 188-192.

23. Rigas B, Torosis J, McDougall CJ, Vener KJ, Spiro HM. The circadian rhythm of biliary colic. J Clin Gastroenterol. 1990; 12: 409-414.

24. Lund J. Surgical indications in cholelithiasis: prophylactic choleithiasis: prophylactic cholecystectomy elucidated on the basis of long-term follow up on 526 nonoperated cases. Ann Surg. 1960; 151: 153-162.

25. Preston JF, Diggs BS, Dolan JP, Gilbert EW, Schein M, Hunter JG. Biliary dyskinesia: a surgical disease rarely found outside the United States. Am J Surg. 2015; 209: 799-803.

26. Bielefeldt K. The rising tide of cholecystectomy for biliary dyskinesia. Aliment Pharmacol Ther. 2013; 37: 98-106.

27. Drossman DA. The functional gastrointestinal disorders and the Rome III process. Gastroenterology. 2006; 130: 1377-1390

28. Tulchinsky M, Ciak BW, Delbeke D, Hilson A, HolesLewis KA, Stabin MG, et al. SNM practice guideline for hepatobiliary scintigraphy 4.0. J Nucl Med Technol. 2010; 38: 210-218. 
29. Vogt DP. Gallbladder disease: an update on diagnosis and treatment. Cleve Clin J Med. 2002; 69: 977-984.

Declaraciones: Ninguno de los autores tiene nada que revelar.
Correspondencia:

Dr. Leopoldo Herrera Chabert

Av. Patria 1891-1509,

Col. Puerta de Hierro, 45116,

Zapopan, Jalisco, México.

Tel: 52 (33) 3813-4092 / (33) 1457-5882

E-mail: doctorchabert@hotmail.com 